\title{
Conducta actual frente la hemorragia digestiva alta: Desde el diagnóstico al tratamiento
}

\author{
Guillermo Martínez S. ${ }^{1}$, Pedro Figueroa N. ${ }^{2}$, Javier Toro P. ${ }^{2}$, \\ Carlos García C. ${ }^{1}$ y Attila Csendes J. ${ }^{3}$
}

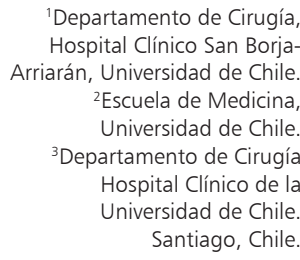

'Departamento de Cirugía, Hospital Clínico San BorjaArriarán, Universidad de Chile. ${ }^{2}$ Escuela de Medicina Universidad de Chile. ${ }^{3}$ Departamento de Cirugía Hospital Clínico de la Universidad de Chile. Santiago, Chile.

Recibido 2020-10-06 aceptado 2020-10-06

Correspondencia a: Dr. Guillermo Martínez S. guillermomartinez@ug.uchile.c

\section{Current behavior against Upper Digestive Hemorrhage: From diagnosis to treatment}

Upper gastrointestinal bleeding (UHD) is a common medical-surgical emergency that must be treated early due to its high morbidity and mortality. It corresponds to bleeding from the esophagus, stomach, or proximal duodenum, and is divided into non-variceal and variceal etiology. Among the non-variceal, the peptic ulcer stands out as the most frequent, being this produced by an imbalance between protective and aggressive factors. On the other hand, in variceal hemorrhages gastroduodenal varices stand out, are a consequence of increased portal pressure. The incidence of HDA worldwide varies between 37 to 172 cases per 100,000 inhabitants per year and mortality between 5 to $14 \%$ according to different studies. Unfortunately, there are no reliable national statistics of incidence and prevalence. The physician must have a good understanding of the clinical presentation and pathophysiology to be assertive in the suspicion, diagnosis, and management of this pathology. Regarding treatment, the confrontation is divided into emergency management and then endoscopic, because early intensive resuscitation can reduce morbidity and mortality in patients with UHD. This is an updated review which will be focused on the most relevant aspects of the management of this pathology. Data were obtained from Pubmed and Scielo, specifically searching for original articles and systematic reviews with the words "upper gastrointestinal bleeding", "peptic ulcer", "esophageal varices" and other related words. The criteria used were articles preferably less than 5 years old in scientific journals with a high impact index.

Key words: upper gastrointestinal bleeding; peptic ulcer; gastroduodenal varices; early resuscitation; endoscopic management.

\section{Resumen}

La hemorragia digestiva alta (HDA) es una emergencia médico-quirúrgica común que debe ser tratada precozmente por su alta morbimortalidad. Corresponde a sangrado del esófago, estómago o del duodeno proximal, y se divide en etiología no variceal y variceal. Dentro de las no variceales destaca la úlcera péptica como la más frecuente, siendo esta producida por un desbalance entre factores protectores y agresivos. Por otro lado, en las hemorragias variceales destacan las várices gastroduodenales, las cuales son consecuencia del aumento de la presión portal. La incidencia de la HDA a nivel mundial varía entre 37 a 172 casos por cada 100.000 habitantes por año y la mortalidad entre un 5 y un $14 \%$ según diferentes estudios. Lamentablemente, no existen cifras nacionales fidedignas de incidencia y prevalencia. El médico debe conocer bien la presentación clínica y la fisiopatología para ser asertivo en la sospecha, diagnóstico y manejo de esta patología. En cuanto al tratamiento, el enfrentamiento se divide en el manejo de urgencias y luego endoscópico, puesto que la resucitación temprana intensiva puede reducir la morbimortalidad en pacientes con HDA. A continuación se hará una revisión actualizada enfocada en los aspectos más relevantes del manejo de esta patología. Se obtuvieron los datos de Pubmed y Scielo, específicamente la búsqueda de artículos originales y de revisiones sistemáticas con las palabras "hemorragia digestiva alta", "úlcera péptica", "várices esofágicas" y otras relacionadas. Los criterios usados fueron artículos preferentemente menores a 5 años de publicación en revistas científicas de alto índice de impacto.

Palabras clave: hemorragia digestiva alta, úlcera péptica; varices gastroduodenales; reanimación temprana; manejo endoscópico. 


\section{Introducción}

La hemorragia digestiva alta (HDA) es una emergencia frecuente comúnmente asociada a elevada morbimortalidad ${ }^{1}$. Esta patología representa un alto costo sanitario y económico y es una causa frecuente en el mundo de hospitalización en los servicios de urgencia ${ }^{2}$. Las etiologías más frecuentes son la úlcera péptica (duodenales y gástricas), gastritis o duodenitis erosiva y aquella asociada a varices, siendo esta última la de mayor mortalidad. El manejo oportuno de esta patología conlleva una mejor sobrevida y calidad de vida de los pacientes ${ }^{3}$.

La HDA se define como un conjunto de signos y síntomas producto de cualquier sangrado proveniente del tracto gastrointestinal proximal al ligamento suspensorio del duodeno o de Treitz ${ }^{1,4}$. Se clasifica según la etiología de origen en variceal o no variceal. La HDA de causa variceal corresponde al sangrado de las várices gastroesofágicas, producto de un aumento de la presión en el sistema vascular portal, permitiendo el reflujo del contenido sanguíneo hacia sistemas venosos de menor capacitancia, produciendo su dilatación y tortuosidad. Por otro lado, la HD no variceal sucede por múltiples causas, siendo las más frecuentes la úlcera péptica gastroduodenal y la gastritis erosiva por AINEs ${ }^{4}$.

\section{Epidemiología}

La HDA constituye uno de los principales motivos de hospitalización por enfermedades del tracto gastrointestinal, y se puede acompañar de una significativa morbimortalidad en grupos de riesgo, como son los pacientes mayores de 65 años. De modo general, la tasa cruda de la HDA a nivel mundial va entre 37 a 172 casos por cada 100.000 habitantes por año ${ }^{5}$. Los factores de riesgo no variceales más comunes, como la úlcera péptica (UP) y el uso de fármacos (AINEs y aspirina) se han asociado a mayores tasas de incidencia y mortalidad ${ }^{6}$. Cabe destacar que la UP provocada por la colonización por $H$. pylori concentra cerca del $60 \%$ a $70 \%$ de casos nuevos cada año 7 . A pesar de los variados factores causantes de la HDA no variceal, se observa una disminución de su incidencia a nivel mundial, gracias al manejo oportuno de la UP y los nuevos tratamientos farmacológicos contra la infección por H. pylori ${ }^{5}$. La mortalidad a nivel mundial ha sido reportada entre $5 \%$ a $14 \%$ en algunos estudios. Sin embargo, reportes recientes mencionan una posible disminución de la mortalidad intrahospitalaria, gracias a los avances médicos de los últimos años ${ }^{8}$.

Respecto a la epidemiología de la HDA en Chile, según datos provenientes del Ministerio de Salud (MINSAL) y del Departamento en Estadísticas e Información en Salud (DEIS) para el año 2018, cerca de 6.000 egresos hospitalarios anuales fueron contabilizados por hemorragias digestivas sin etiología específica. En un estudio realizado por Pávez y cols. ${ }^{9}$ en el año 2010 demostraron una mortalidad de la HDA no variceal cercano al 9\%. A esto se le suma otro estudio retrospectivo hecho por Pinto y cols. ${ }^{10}$ en el Hospital Clínico de la Universidad de Chile (HCUCh), quienes comprobaron que la mortalidad por HDA entre los años 2015 al 2017 alcanzó un $6,8 \%$ de mortalidad global ${ }^{10}$. No existen cifras nacionales que puedan asegurar los valores de incidencia y prevalencia de manera certera con respecto a la HDA variceal o no variceal, debido especialmente a la poca disponibilidad de este tipo de información en las estadísticas sanitarias.

\section{Etiología y fisiopatología}

Las causas se muestran en la Tabla 1 y Tabla 2 . Existen diversos mecanismos fisiopatológicos en la HDA variceal y no variceal. A continuación, se pro-

Tabla 1. Causas frecuentes de HDA no variceal. Adaptado de Tavakkoli y Ashley ${ }^{11}$

\begin{tabular}{|lcll|}
\hline \multicolumn{4}{|c|}{ Causas frecuentes de hemorragia digestiva alta, reportes internacionales } \\
Hemorragia no variceal & $80 \%$ & Hemorragia variceal & $20 \%$ \\
Úlcera péptica & $30-40 \%$ & Varices gastroesofágicas & $>90 \%$ \\
Gastritis y duodenitis & $20 \%$ & Gastropatía por hipertensión portal & $<5 \%$ \\
Esofagitis & $5-10 \%$ & \\
Desgarro de Mallory Weiss & $5-10 \%$ & \\
Malformaciones arteriovenosas & $5 \%$ & \\
Tumores & $2 \%$ & \\
Otras causas & $5 \%$ & \\
\hline
\end{tabular}




\section{ARTíCULO DE REVISIÓN}

Tabla 2. Etiologías frecuentes de la HDA variceal y no variceal en 249 pacientes del HCUCh entre el año 2015 y $2017^{10}$

\section{Causas de hemorragia digestiva alta, reportes nacionales} entre el año 2015 - 2017

\begin{tabular}{lc|} 
HDA variceal & $28 \%$ \\
HDA no variceal & $72 \%$ \\
Úlcera péptica & $44 \%$ \\
Gastropatía / duodenopatía erosiva & $11 \%$ \\
Esofagitis erosiva / úlcera esofágica & $10 \%$ \\
Neoplasia gastrointestinal & $5 \%$ \\
Síndrome de Mallory-Weiss & $4 \%$ \\
Lesión de Dieulafoy & $4 \%$ \\
Angiodisplasia & $2 \%$ \\
Ectasia vascular gástrica antral & $2 \%$ \\
Úlcera / erosión de la anastomosis gastroyeyunal & $4 \%$ \\
Endoscopía digestiva alta normal & $2 \%$ \\
Otras causas & $10 \%$ \\
\hline
\end{tabular}

cederá a explicar la fisiopatología de las causas más frecuentes de esta patología en la Tabla 3 y Tabla 4.

\section{Manifestaciones clínicas}

El espectro de los síntomas y signos de este síndrome es amplio, pudiendo presentarse pacientes asintomáticos, anémicos o hasta la presencia de una hemorragia masiva con shock hipovolémico ${ }^{11}$. Por lo que, cuando un paciente acude con este síndrome, es importante realizar un abordaje estructurado para su valoración. La realización de una exhaustiva anamnesis se centra en buscar síntomas que sugieran la localización del origen del sangrado (Tabla 5).

\section{Diagnóstico}

El diagnóstico de la HDA es eminentemente clínico la mayoría de las veces, cuando la clínica permite sospechar la patología. En la práctica clínica, el diagnóstico y el manejo se entrelazan ${ }^{4}$. Existen varios exámenes de laboratorio, imagenológicos y procedimientos que permiten el estudio diagnóstico de este síndrome y de su etiología que se detallan más adelante.

Tabla 3. Fisiopatología de las etiologías más frecuentes de HDA variceal y no variceal

\section{Fisiopatología de las causas más frecuentes de la HDA}

\section{Úlcera péptica (UP)}

Se define como aquella solución de continuidad de la mucosa de más de 3-5 mm de diámetro mayor, que está constantemente expuesta a pepsina y ácido clorhídrico, con infiltración inflamatoria y necrosis, que alcanza en profundidad la capa muscular, pudiendo extenderse a todo el espesor del órgano, inclusive produciendo su perforación. Por lo tanto, la úlcera péptica siempre deja una cicatriz cuando desaparece, al contrario de las erosiones, que son lesiones que llegan hasta la submucosa y siempre cicatrizan "ad integrum" sin dejar cicatriz. Anatómicamente, se producen con mayor frecuencia en el estómago y en la primera porción del duodeno 3 (Figura 1).

La infección por H. pylori está presente en 75\%-95\% de los casos de úlcera duodenal (UD) y en 60-80\% de los casos de úlcera gástrica. En Chile, se demostró la presencia de H. pylori en $88 \%$ de los pacientes con UD 3 .

En el estómago y el duodeno existen factores defensivos y agresivos de la mucosa. Dentro de los factores defensivos se distingue el mucus producido por el epitelio simple cilíndrico de la mucosa gastroduodenal, el bicarbonato, flujo sanguíneo, prostaglandinas y las uniones intercelulares (tight-junctions). Por otro lado, los factores agresivos se pueden subdividir en dos: (1) Exógenos: H. Pylori, AINEs, Ácido acetilsalicílico (AAS), alcohol, tabaco, otros; (2) endógenos: ácido + pepsina, contenido duodenal (Figura 2 y 3$)^{3}$.

Clásicamente, los factores protectores se han dividido en (1) preepiteliales, que corresponden a la capa de mucus, y bicarbonato; (2) Epiteliales, que se representan como la regeneración celular y la capa de fosfolípidos en conjunto con las uniones intercelulares; (3) Posepiteliales, destacan las prostaglandinas y el flujo sanguíneo (Tabla 4).

Las úlceras surgen por un desbalance entre los factores protectores y agresivos. En las UG existe predominio de la disminución de los factores protectores, mientras que en las UD hay predominio del aumento de factores agresores.

\section{Desgarro de Mallory Weiss}

Esta lesión se caracteriza por la presencia de laceraciones longitudinales superficiales de la mucosa en la parte superior del estómago (cardias). Este síndrome es el resultado de muchos factores, donde se incluye el rápido aumento de la presión en el cardias ${ }^{4}$, como lo que ocurre cuando hay múltiples episodios de vómitos posterior al consumo de alcohol ${ }^{12}$. Producto del aumento brusco de presión, se produce una hiperextensión del estómago que limita la movilidad entre la mucosa y la submucosa, resultando en un cierre insuficiente del cardias ${ }^{4}$.

Sumado a lo anterior, las contracciones musculares desincronizadas de las diferentes capas de la parte inferior del esófago y el cardias, junto con la disposición longitudinal de los pliegues de la mucosa en la unión gastroesofágica, provocan laceraciones lineales profundas de la mucosa. Esto genera la exposición de los vasos submucosos al ácido, provocando que se dañen y se produzca la hemorragia ${ }^{4}$. Este desgarro usualmente suele ser longitudinal y única, y la lesión tiene una alta probabilidad de cesar espontáneamente el sangrado. La intervención endoscópica sólo es requerida en un $10 \%$ de los $\operatorname{casos}^{13}$ (Figura 4). 


\section{Malformaciones vasculares}

Dentro de esta patología se encuentra el síndrome de Dieulafoy y las ectasias vasculares. Normalmente, una arteria en el tracto gastrointestinal se va estrechando a medida que llega a su destino final ${ }^{14}$. En el síndrome de Dieulafoy se produce un sangrado producto de una arteria histológicamente normal, pero anormalmente grande $(1-3 \mathrm{~mm})$ que tiende a penetrar en la submucosa ${ }^{4}$. Además, presenta un recorrido tortuoso con protrusión hacia la mucosa producto de un defecto pequeño de la mucosa $(2-5 \mathrm{~mm})$ asociado a una base fibrinonecrótica. Típicamente esta lesión se ubica en el tercio superior del estómago ya sea en la curvatura menor o más frecuente en la mayor, lugar donde hay mayor cantidad de defectos en la mucosa para la protrusión del vaso ${ }^{14}$ (Figura 5).

Las ectasias vasculares tienen una patogenia similar a la lesión de Dieulafoy. Estas son vénulas dilatadas que forman estrías lineales de color rojo que convergen longitudinalmente en el antro, produciendo una imagen de sandía ${ }^{11}$. Se ha propuesto que para la formación de estas debe existir una obstrucción venosa de la submucosa intermitente, un flujo sanguíneo intermitente y degeneración vascular local con hipoxemia local. Esta patología tiene asociación con comorbilidades cardíacas, renales, etc. Las ectasias vasculares, a menudo múltiples o difusas, ocurren frecuentemente en el antro gástrico, lo que puede estar relacionado con la contracción muscular más vigorosa del antro, lo que predispone a la obstrucción venosa ${ }^{4,15}$ (Figura 6).

\section{Varices gastroesofágicas}

La formación de las colaterales portosistémicas se debe a la aparición de hipertensión portal ${ }^{3}$, las que se producen por un factor hemodinámico que consta de un aumento de la resistencia (intrahepática, portal o colateral) y aumento del flujo sanguíneo (vasodilatación esplácnica y sistémico asociado a hipervolemia) (Figura 7). Las varices esofágicas son el resultado del aumento de la presión portal desde los $10 \mathrm{mmHg}$, con un riesgo aumentado de sangrado con un gradiente de $12 \mathrm{mmHg}^{12}$.

Tabla 4. Aspectos fisiológicos y agresores de la mucosa gástrica

\section{Factores protectores y agresores en la fisiopatología de la UP}

\section{Factores preepiteliales}

Las primeras defensas que tiene la mucosa gástrica son la barrera de mucus y el bicarbonato $\left(\mathrm{HCO}_{3}^{-}\right)$. Esta capa tiene la capacidad de retener los iones bicarbonato secretados por las células epiteliales superficiales y de mantener el $\mathrm{pH}$ cercano a 7 en la proximidad de la mucosa ${ }^{16}$.

La barrera mucus-bicarbonato es el único sistema que separa el epitelio gastroduodenal del lumen gástrico. Por lo tanto, cuando la barrera protectora se rompe durante ciertos estados patológicos o bajo la influencia de agentes lesivos, se activan otros mecanismos de protección Estos incluyen la neutralización del ácido intracelular, renovación rápida del epitelio y mantenimiento del flujo sanguíneo de la mucosa ${ }^{17}$.

\section{Factores epiteliales}

La capa continua de células mucosas superficiales están estrechamente interconectadas por medio de tight juctions o uniones estrechas. Esta barrera epitelial representa la siguiente línea de defensa de la mucosa. Debido a la presencia de uniones estrechas, estas células forman una barrera impermeable que evita el paso de ácido gástrico y pepsina a las capas más profundas del revestimiento gástrico ${ }^{16}$. Las células epiteliales, debido a la presencia de fosfolípidos en su membrana plasmática, son hidrófobas y pueden repeler los agentes solubles en agua y en ácido responsables del daño de las mucosas ${ }^{17}$.

Ahora bien, esta integridad de la capa de mucosa se mantiene mediante un proceso constante de renovación celular por las células progenitoras de la mucosa y por la presencia de prostaglandinas. El proceso de renovación epitelial completa toma alrededor de 3 a 7 días, mientras que la restitución del epitelio después de la exposición a agentes lesivos ocurre en minutos y depende de la migración de células preservadas desde el área del cuello de las glándulas gástricas ${ }^{16,17}$

\section{Factores posepiteliales}

La mucosa gástrica se caracteriza por la producción constante de prostaglandinas, especialmente $\mathrm{PGE}_{2}$ y $\mathrm{PGI}_{2}$, que desempeñan un papel crucial en el mantenimiento de la integridad de la mucosa y la protección contra factores dañinos. En particular, tienen potencial para reducir la producción de ácido, estimular la producción de moco y bicarbonato, así como aumentar el flujo sanguíneo de la mucosa. Además, las prostaglandinas son responsables de la aceleración de la restitución epitelial y la curación de la mucosa ${ }^{18}$. Dentro de los roles que además tienen las prostaglandinas es mantener un flujo sanguíneo adecuado en las mucosas. Esto es crucial para suministrar sustancias indispensables, como nutrientes y oxígeno, y para eliminar los metabolitos tóxicos de la mucosa gástrica ${ }^{19}$.

\section{Factores agresivos}

H. pylori es una espiroteca gram negativa, productora de ureasa, que metaboliza la urea a amonio y le permite sobrevivir en el ambiente ácido del estómago ${ }^{3}$. La infección por esta bacteria se caracteriza por una abundante respuesta inflamatoria histológica y lesión de las células epiteliales gástricas. La gastritis por H. pylori se caracteriza por la infiltración de la mucosa gástrica con células inflamatorias, como leucocitos polimorfonucleares, linfocitos, células plasmáticas y macrófagos ${ }^{19}$. Es de destacar que es bien sabido que la infección por $H$. pylori induce estrés oxidativo crónico en la mucosa gástrica, lo que provoca daño y retraso en la reparación de la mucosa. Dentro de otros roles patogénicos que tiene la $H$. pylori es que producto de la inflamación generada, las células D productoras de somatostatina se comienzan a destruir, lo que produce un aumento de la gastrina (por desinhibición de las células $\mathrm{G}$ antrales) y de la histamina (por desinhibición de las células Enterocromafin-like [ECL]), produciendo hipergatrinemia e hiperhistaminemia, conllevando a una mayor injuria por ácido y pepsina ${ }^{20}$ (Figura 2).

Los AINEs bloquean las ciclooxigenasas; por tanto, la lesión gástrica relacionada con su administración está estrechamente asociada con la inhibición de la producción de prostaglandinas que tienen diversas funciones antes comentadas ${ }^{19}$ (Figura 3). 


\section{ARTíCULO DE REVISIÓN}

Tabla 5. Hallazgos clínicos concomitantes a una HDA que pueden orientar a una etiología subyacente

\begin{tabular}{|c|c|}
\hline \multicolumn{2}{|r|}{ Hallazgos en la evaluación clínica de HDA variceal o no variceal } \\
\hline Anamnesis próxima & $\begin{array}{l}\text { Indagar por dolor de tipo ulceroso, que presente periodicidad y ritmicidad, compromiso de estado general (anorexia, } \\
\text { adinamia, astenia), náuseas, vómitos. Detallar con exactitud la cantidad y las características del sangrado intestinal para } \\
\text { pesquisar la localización del sangrado (hematemesis, melena, hematoquezia). }\end{array}$ \\
\hline Anamnesis remota & $\begin{array}{l}\text { Antecedentes de uso crónico de AINEs, antiagregantes plaquetarios o anticoagulantes, episodios similares anteriormen- } \\
\text { te }^{2} \text {, antecedentes de inserción de prótesis que pueden tener relación con el sangrado (stents coronarios y antiagregantes } \\
\text { plaquetarios, válvulas cardiacas y anticoagulantes, prótesis aórticas y el riesgo de fístulas aorto-intestinales) } \text { s }^{22} \text { y esfuer- } \\
\text { zos repetitivos de reflejo nauseoso. También se debe averiguar si presenta antecedentes de daño hepático crónico por } \\
\text { consumo crónico de alcohol u otra causa subyacente }{ }^{3} \text {. }\end{array}$ \\
\hline Examen físico & $\begin{array}{l}\text { Los signos vitales evaluados en el examen físico general que permiten sospechar una HDA son la presencia de hipo- } \\
\text { tensión y taquicardia, pues brindan información acerca de la severidad del sangrado }{ }^{2} \text {. } \\
\text { En el examen físico segmentario se debe evaluar la presencia de hematemesis (signo más frecuente), melena (presencia } \\
\text { del } 90 \%)^{4} \text { y hematoquecia (presente en un } 15 \% \text { de los casos). Para evaluar estos signos es importante la realización de } \\
\text { un tacto rectal }{ }^{3} \text {. Además, se pueden encontrar ciertos signos de DHC tales como circulación colateral, ascitis, telangiec- } \\
\text { tasias, ictericia, hepatoesplenomegalia, parotidomegalia bilateral, ginecomastia, etc. } .^{2,3} \text {. }\end{array}$ \\
\hline
\end{tabular}

Figura 1. Úlcera péptica forrest IIA. Gentileza de equipo de gastroenterología y endoscopia HCUCh.

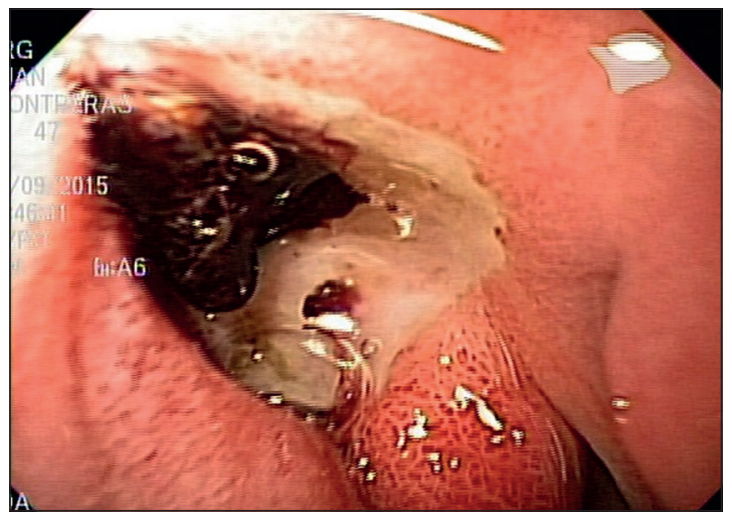

\section{Manejo y tratamiento}

\section{Manejo preendoscópico}

Una buena anamnesis y examen físico permiten realizar una sospecha clínica precoz, donde la confirmación de hematemesis y melena son claves, haciéndose necesario establecer el origen del sangrado. Además, realizar una valoración de la severidad con una estratificación del riesgo es fundamental para el pronóstico del paciente ${ }^{3}$. Por otro lado, se sospecha esta patología en los pacientes asintomáticos gracias a exámenes de laboratorio como un hemograma o un test de sangre ocultas ${ }^{11}$, por lo cual se debe realizar

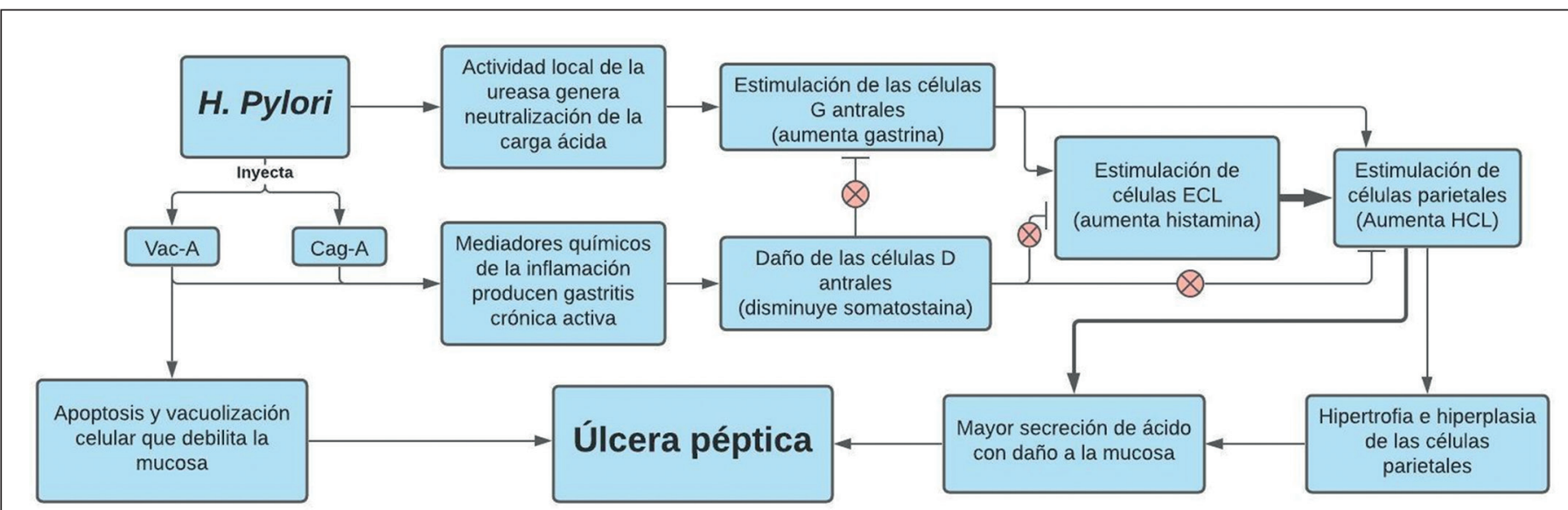

Figura 2. Esquema resumido de la fisiopatología de la infección por $H$. pylori en la zona antral del estómago. La producción local de diversas enzimas (proteasas, fosfolipasas, ureasa, etc.) más los factores patogénicos de esta bacteria, como citotoxina CagA y VacA, entre otros, lesionan e inflaman la mucosa gastroduodenal, generando un daño a las células $\mathrm{D}$ productoras de somatostatina. La disminución de esta determina la desinhibición de las células $\mathrm{G}$ antrales productoras de gastrina, y, además, la desinhibición de las células ECL productoras de histamina. Esto conlleva la generación de una mayor secreción de ácido por parte de las células parietales, actuando como el factor agresor endógeno condicionante de la úlcera péptica. H. pylori: Helicobacter pylori; ECL: Enterocromafin-like. 


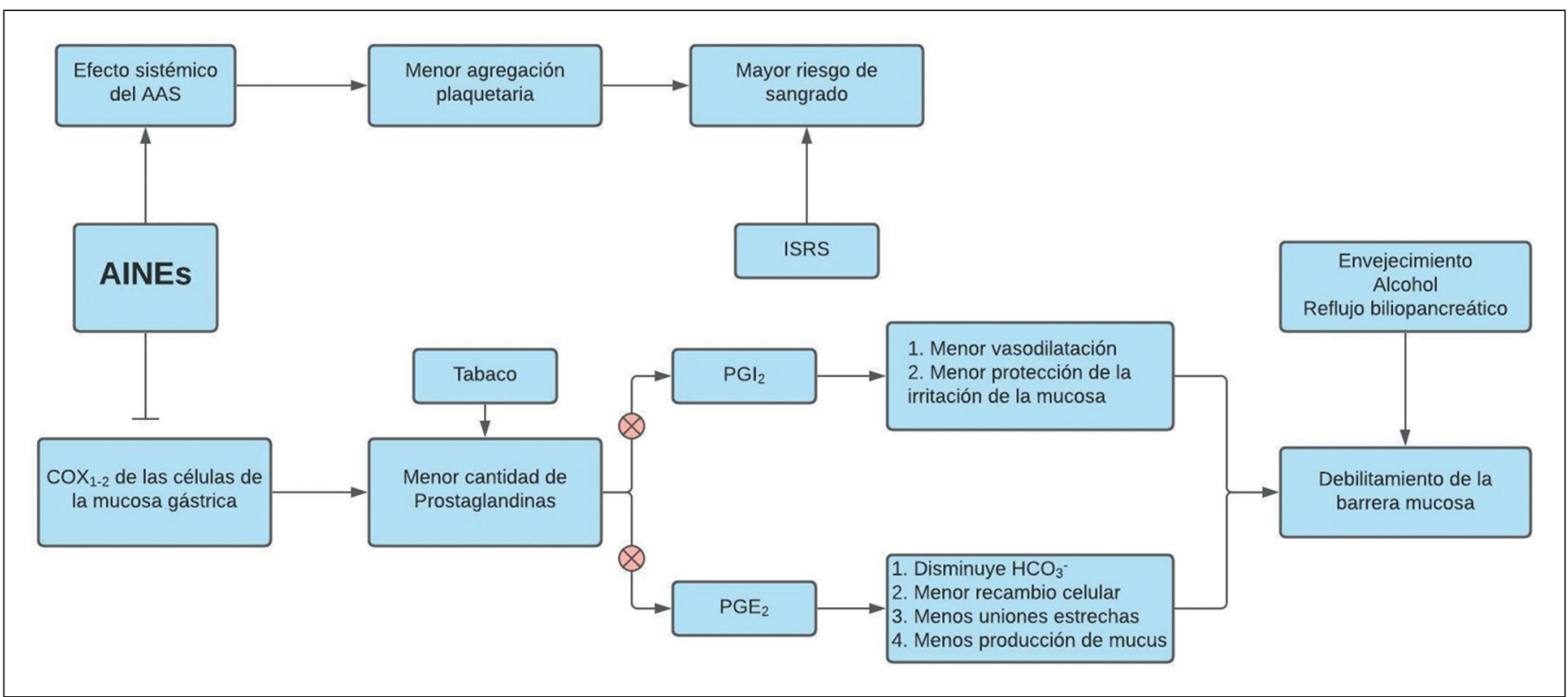

Figura 3. Otros agentes agresores. La familia de los AINEs inhibe las enzimas COX 1 y COX 2 disminuyen producción de prostaglandinas (PG) en las células de la mucosa gástrica. Dado el rol crucial de las PG en sustentar la eficiencia de la barrera mucosa, estas alteraciones predisponen a un mayor riesgo de daño por factores agresores, determinando un mayor riesgo de generar una úlcera péptica. A su vez, el AAS tiene un efecto dañino directo sobre la mucosa por ser un ácido débil, por lo que, cuando ingresa a la célula de la mucosa gástrica libera sus protones de manera local dañándola. Por otro lado, el AAS tiene efectos sistémicos al impedir la agregación plaquetaria, produciendo un mayor riesgo de sangrado de la úlcera péptica. Además, los ISRS aumentan el riesgo de sangrado. Finalmente, el envejecimiento produce debilitamiento de la barrera mucosa, y tanto el alcohol con el reflujo biliopancreático producen un daño directo. Por otro lado, el tabaquismo contribuye a un mayor daño por un efecto tóxico, disfunción endotelial y menor capacidad de secreción de HCO3-. AINEs: Antiinflamatorio no esteroidal; AAS: ácido acetil salićlico; PGI2: Prostaglandina I2 o prostaciclina; PGE2: Prostaglandina E2; ISRS: Inhibidores selectivos de la recaptación de serotonina.

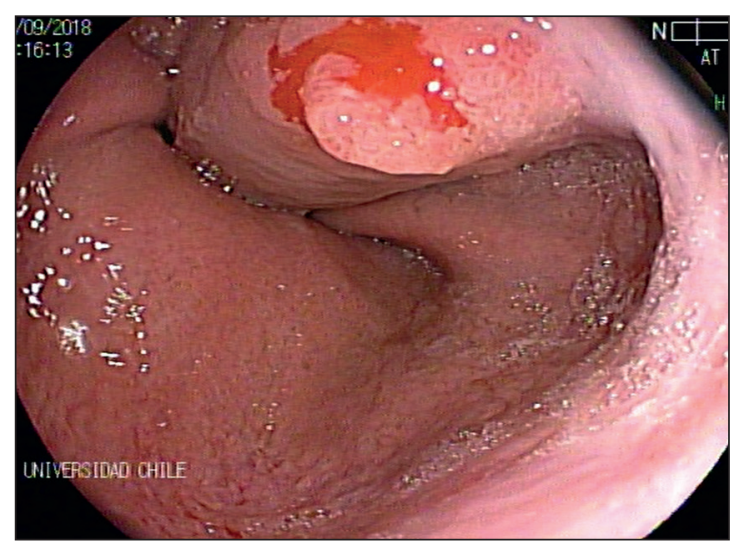

Figura 4. Lesión de Mallory Weiss. Gentileza del equipo de gastroenterología y endoscopia HCUCh.

una serie de exámenes de laboratorio básicos para confirmar la sospecha clínica, los que se detallan en la Tabla 6.

El manejo comienza desde el momento de la presentación del paciente al servicio de salud con una rápida valoración inicial para determinar la



Figura 5. Lesión de Dieulafoy. Gentileza del equipo de gastroenterología y endoscopia HCUCh.

urgencia de la situación. Para esto se procederá a realizar una evaluación primaria y secundaria. La evaluación primaria consistirá en evaluar la vía aérea, respiración y la circulación, y la evaluación secundaria en completar la historia y el examen físico ${ }^{12}$. 
Figura 6. Ectasia vascular antral gástrica (GAVE, por sus siglas en inglés) Gentileza del equipo de gastroenterología y endoscopia HCUCh.

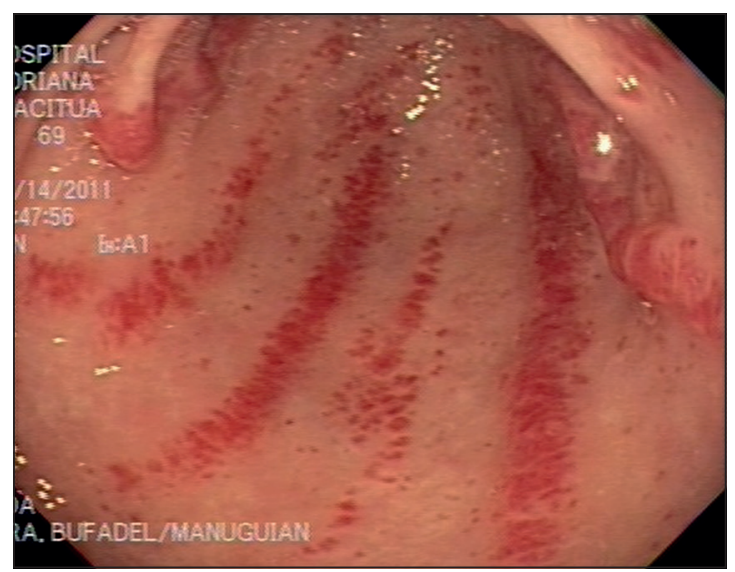

La razón de dividir prioridades cuando ingresa un paciente con este cuadro es porque evidencia existente demuestra que la resucitación temprana intensiva con la corrección de parámetros hemodinámicos, hemoglobina y coagulopatías pueden reducir la mortalidad en pacientes con $\mathrm{HDA}^{13,14}$. Entonces, es imperativo recordar que el tratamiento inicial de cualquier paciente con HDA es la reanimación ${ }^{15}$. Esta consiste en la restauración de la volemia utilizando fluidos intravenosos (cristaloides o Ringer-lactato), transfusiones de sangre y oxígeno complementario.

En un paciente con sangrado intestinal masivo, es imprescindible controlar la fuente de la hemorragia antes de seguir con el protocolo de manejo habitual de estos pacientes ${ }^{12}$. Afortunadamente la mayoría de las HDA son autolimitadas o el pa-
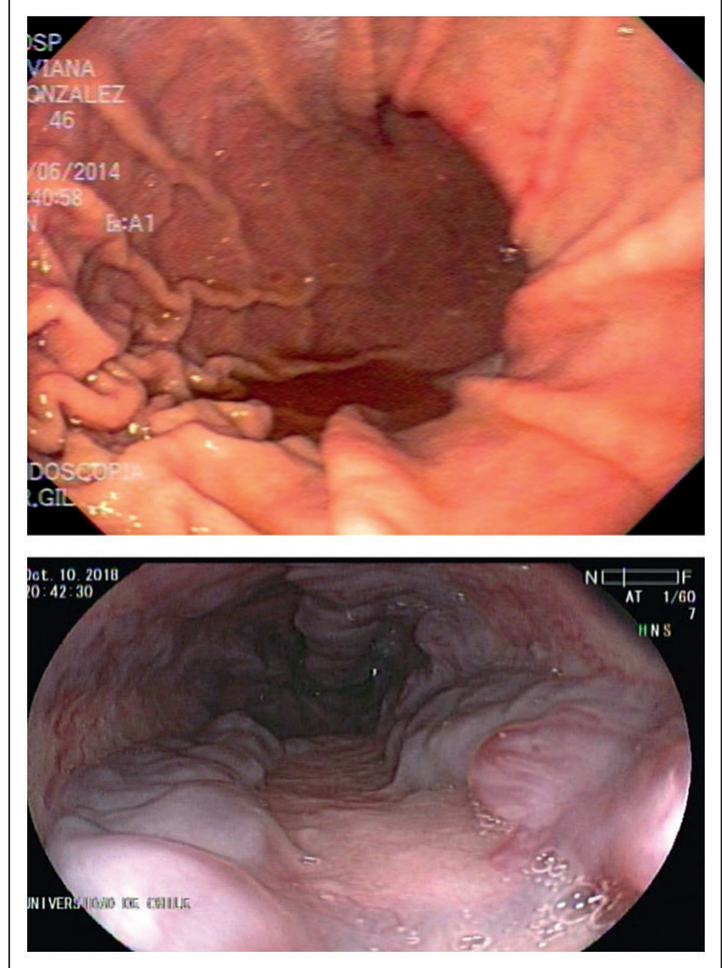

Figura 7. Várices gástricas (superior) y várices esofágicas con signos de riesgo de sangrado vistas por endoscopía. Gentileza del equipo de gastroenterología y endoscopia HCUCh.

ciente está lo suficientemente estable como para realizar la evaluación secundaria ${ }^{15}$. En el caso de que la atención médica primaria no sea capaz de proporcionar un control definitivo de la hemorragia, se recomienda realizar la derivación oportuna

Tabla 6. Exámenes de laboratorios básicos para el estudio de la HDA

\section{Exámenes de laboratorio a solicitar para apoyar a la evaluación del paciente}

Hemograma con VHS: En este examen podría verse alterado el hematocrito (Hto), la hemoglobina (Hb) y el recuento de glóbulos rojos. Sin embargo, estos parámetros no son muy útiles en la fase aguda ya que no tienden a disminuir, sólo reduciéndose a medida que el organismo recupera su volemia. Tener en cuenta la hemoglobina para necesidad de transfusión. La hemodilución ocurre varias horas después del sangrado.

Pruebas de coagulación: Este examen principalmente tiene utilidad para enfermos con terapias anticoagulantes o para descartar alguna coagulopatía. En este caso los más relevantes son el tiempo de sangría, TTPa e INR.

Creatinina: La hipovolemia generada por el sangrado intestinal puede producir una disminución de la perfusión renal, lo que puede conllevar a una AKI prerrenal. Es importante tener en consideración este parámetro, ya que la reanimación precoz con fluidos permitiría mejorar la función renal

Electrolitos plasmáticos (ELP): Pueden encontrarse alteraciones electrolíticas dependiendo de la etiología de la hemorragia digestiva alta, como, por ejemplo, una hiponatremia en el daño hepático crónico o pérdida de volumen extracelular, o hipernatremia si el sangrado ha sido por más tiempo generando hemoconcentración. Hipermagnesemia, hiper o hipokalemia agravada por acidosis metabólica.

Grupo Rh y ABO: Siempre se deben solicitar ante una eventual necesidad de transfusión sanguínea

Lactatemia y Base Excess: Son marcadores de hipoperfusión tisular. 


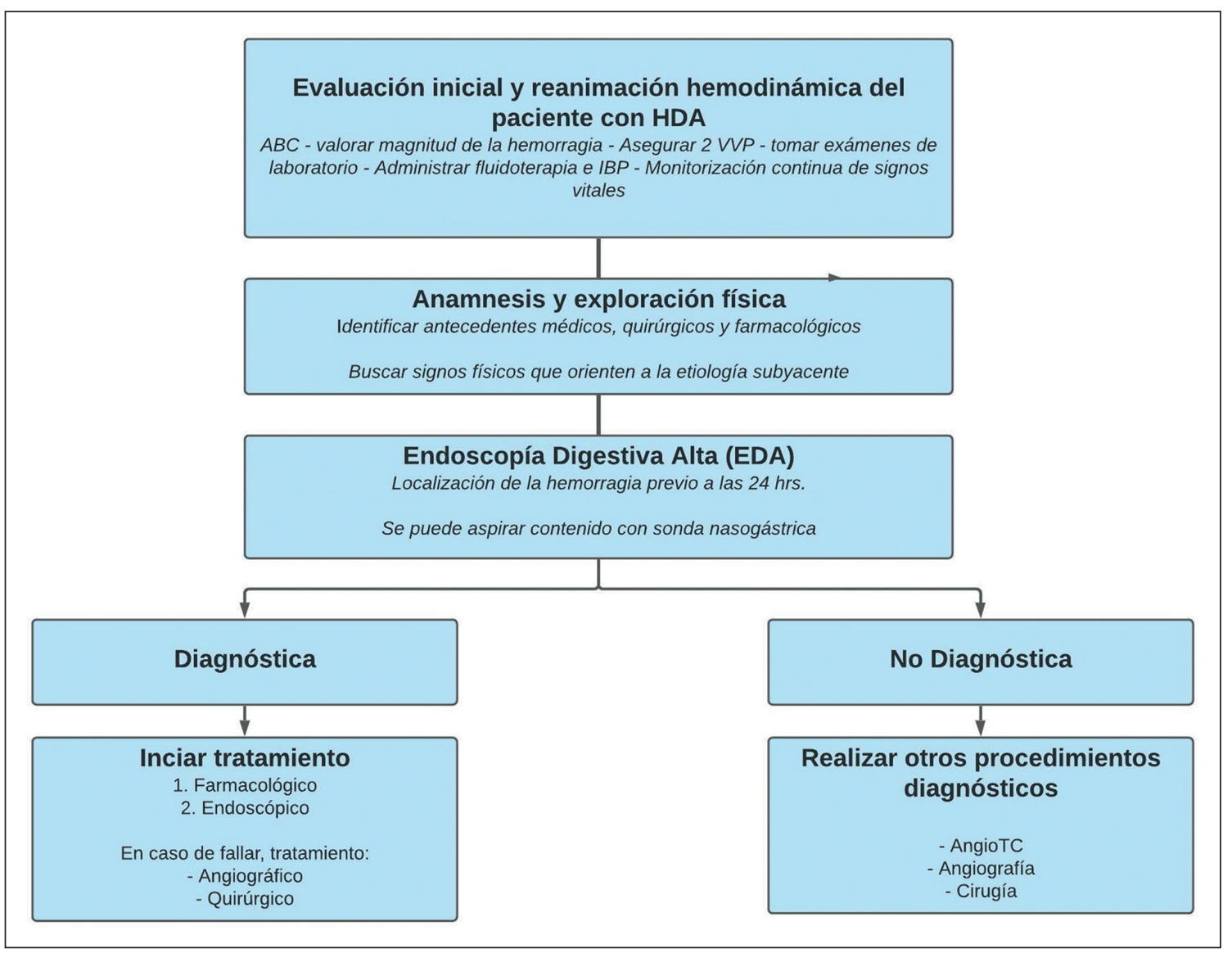

inmediata a un centro de mayor complejidad. Por otro lado, si el paciente se encuentra estable en la evaluación primaria, y en la secundaria no se pesquisan comorbilidades que aumenten el riesgo de futuras complicaciones, el paciente podría potencialmente tratarse ambulatoriamente ${ }^{12}$. En la Figura 8 se propone un algoritmo para la evaluación primaria y secundaria.

\section{Evaluación primaria}

Esta corresponde al ABC del trauma aplicada a esta urgencia médico-quirúrgica, con una resucitación temprana (Tabla 7). Además, se deben valorar las pérdidas sanguíneas para instaurar una buena terapia de reanimación (Tabla 8).

Se debe hacer uso de sistemas de estratificación del riesgo. Las escalas validadas para esto son la Clasificación de Rockall y la escala de GlasgowBlatchford. La Clasificación de Rockall (Tabla 9) tiene como propósito principal predecir la mortalidad y riesgo de resangrado del paciente con HDA, y según eso estimar la realización de una endoscopia digestiva alta (EDA) previo o durante el manejo ${ }^{9}$. La escala de Glasgow-Blatchford (Tabla 10) consiste en la utilización de 5 parámetros (BUN, hemoglobina, presión arterial sistólica, pulso, otros marcadores) para evaluar el riesgo. Ha demostrado una mayor utilidad y superioridad a la anterior en múltiples estudios previos ${ }^{16}$, pues permite la evaluación del riesgo de los pacientes con HDA en función de una serie de variables clínicas y cuantitativas sin realización previa de una EDA. Además, estima la mortalidad y pronóstico del paciente. Su principal uso es identificar los pacientes de alto riesgo que sanguínea o incluso intervención quirúrgica para el control de la $\mathrm{HDA}^{17}$.

\section{Manejo médico}

El uso de terapia médica es uno de los pilares para el control del sangrado, así como resolver las diversas etiologías. Consiste en: van a necesitar de una EDA de urgencia, transfusión
Figura 8. Algoritmo para la evaluación primaria y secundaria de la HDA. Adaptado de Tavakkoli y Ashley ${ }^{11}$. 


\section{Tabla 7. Adaptada de Feinman \& Haut ${ }^{12}$}

\section{Evaluación primaria y resucitación inicial}

1. Evaluar con $\mathrm{ABC}$ : Vía aérea, respiración y circulación.

A: Vía aérea (Airway) y B: Ventilación (Breathing)

La vía aérea y la ventilación son siempre la prioridad inicial, por lo que su evaluación debe hacerse lo antes posible ${ }^{13}$. Los pacientes pueden tener la vía aérea comprometida, sobre todo los pacientes hipoxémicos requirentes de oxígeno suplementario a través de naricera nasal. Otros casos más graves son aquellos pacientes con hematemesis masiva, pues pueden aspirar sangre y provocar un compromiso respiratorio. Se podría considerar una intubación profiláctica antes de la endoscopia ${ }^{24}$.

C: Circulación (Circulation)

Lo primero que se debe hacer es valorar las pérdidas sanguíneas en virtud de signos clínicos que se muestran en la Tabla 8. La importancia de esta valoración es permitir una adecuada reanimación con fluidos, transfusiones o drogas vasoactivas dependiendo de la severidad.

2. Asegurar al paciente y proteger vía aérea

a. Considerar ventilación mecánica profiláctica previo a la endoscopía.

3. Asegurar 2 vías intravenosas periféricas de gran calibre.

a. Se puede considerar un catéter venoso central de gran calibre o una vía intraósea en caso de necesitar transfundir rápidamente.

4. En caso de hipotensión y sangrado abundante resucitar con transfusión 1:1:1 de sangre.

5. Solicitar estudios de laboratorio: Hemograma, grupo ABO y Rh, perfil bioquímico (Crea, BUN, ELP y glucosa), perfil hepático y pruebas de coagulación.

6. Administrar Inhibidores de la Bomba de Protones (IBP) preendoscópicos. Bolo intravenoso de $80 \mathrm{mg}$ asociado a infusión continua de $8 \mathrm{mg} / \mathrm{h}$

7. Considere usar la sonda de Sengstaken-Blakemore para el control temporal de la hemorragia cuando los tratamientos médicos o endoscópicos fallan.

Tabla 8. Clasificación del shock hemorrágico. Adaptada de Spahn y cols. ${ }^{26}$

\begin{tabular}{|c|c|c|c|c|}
\hline \multicolumn{5}{|c|}{ Clasificación de la severidad de la Hemorragia según la ACS/ATLS* } \\
\hline Criterio & I & II & III & IV \\
\hline Pérdida de sangre $(\mathrm{mL})$ & $<750$ & $750-1.500$ & $1.500-2.000$ & $>2.000$ \\
\hline Presión sanguínea & Normal & Normal & Disminuida & Disminuida \\
\hline Frecuencia respiratoria $(\mathrm{Rpm})$ & $14-20$ & $20-30$ & $30-40$ & $>40$ \\
\hline Status mental & Un poco ansioso & Levemente ansioso & Ansioso, confundido & Letárgico \\
\hline
\end{tabular}

*Los valores están estimados para adultos de $70 \mathrm{Kg}$ de peso.

1. Inhibidores de la bomba de protones: Las infusiones de IBP son utilizadas en sospecha de una HDA. La activación de la pepsina intragástrica por el medio ácido inhibe la agregación plaquetaria y facilita la ruptura de los coágulos ${ }^{18}$. La administración precoz de IBP acelera la reepitelización de la mucosa gástrica ${ }^{4}$.

2. Drogas prokinéticas: La administración de estas drogas como metoclopramida o eritromicina han demostrado mejorar el rendimiento diagnóstico endoscópico en pacientes con HDA no variceal. Además, reducen la necesidad de repetir la $\mathrm{EDA}^{12}$
3. Vasoconstrictores esplácnicos: Este grupo está formado por el octreotide (análogo de somatostatina) y terlipresina (análogo de vasopresina).

4. Antibióticos: Se recomiendan antibióticos para todas las várices con hemorragia aguda, debido a una alta tasa de infección agravante que repercute en el pronóstico y etiopatogenia de la hemorragia. Producto del sangrado de las varices estos pacientes tienen riesgo de desarrollar peritonitis bacteriana espontánea. Existe evidencia de que un tratamiento de 7 días con un antibiótico de amplio espectro reduciría las tasas de resangrado ${ }^{12}$. 
Tabla 9. Score de riesgo de mortalidad de Rockall. Adaptada de Ebrahimi y cols. ${ }^{27}$

\begin{tabular}{|c|c|c|c|c|c|}
\hline \multicolumn{6}{|c|}{ Score de riesgo de Rockall } \\
\hline \multirow{2}{*}{\multicolumn{2}{|c|}{ Variables }} & \multicolumn{4}{|c|}{ Puntaje } \\
\hline & & 0 & 1 & 2 & 3 \\
\hline \multirow[t]{2}{*}{ Estado de shock } & PAS (mmHg) & $\geq 100$ & $\geq 100$ & $<100$ & \\
\hline & FC (lpm) & $<100$ & $\geq 100$ & & \\
\hline Diagnóstico & & $\begin{array}{l}\text { Desgarro de Mallory- } \\
\text { Weiss, sin lesión iden- } \\
\text { tificada y sin signos de } \\
\text { hemorragia reciente }\end{array}$ & $\begin{array}{l}\text { Todos los demás } \\
\text { diagnósticos }\end{array}$ & $\begin{array}{l}\text { Neoplasia maligna en } \\
\text { el tracto gastrointestinal } \\
\text { alto }\end{array}$ & \\
\hline
\end{tabular}

PAS: Presión arterial sistólica, FC: frecuencia cardiaca. El rango de puntaje es de 0 - 11. Un puntaje $\leq 3$ predice riesgo de mortalidad bajo, mientras que $\geq 8$ predice un riesgo de mortalidad elevado.

Tabla 10. Score de Glasgow-Blatchford. Adaptada de Rickard y cols. ${ }^{28}$

\begin{tabular}{|lcc|}
\hline Score de Glasgow-Blatchford & & \\
Marcadores de riesgo & Parámetros & Puntaje \\
Nitrógeno ureico en la sangre $(\mathrm{mg} / \mathrm{dL})$ & {$[18,2-22,4)$} & 2 \\
& {$[22,4-28,0)$} & 4 \\
Hemoglobina $(\mathrm{g} / \mathrm{dL})$ en hombres & {$[28,0-70,0)$} & 6 \\
& $\geq 70.0$ & 3 \\
\hline Hemoglobina $(\mathrm{g} / \mathrm{dL})$ en mujeres & {$[12,0-13,0)$} & 6 \\
\hline Presión arterial sistólica (mmHg) & {$[10,0-12,0)$} & 1 \\
& $<10,0$ & 6 \\
\hline Frecuencia cardiaca (latidos por minuto) & {$[10-12,0)$} & 1 \\
Otros marcadores & $<10,0$ & 2 \\
& {$[100-109)$} & 3 \\
\hline
\end{tabular}

El rango de puntaje es de $0-29$. Un puntaje $\geq 0$ es un grupo de alto riesgo. *Antecedente médico, o hallazgos clínicos y laboratorio de enfermedad hepática aguda o crónica. **Antecedente médico, o hallazgo clínico y ecocardiográfico de insuficiencia cardiaca. 


\section{ARTíCULO DE REVISIÓN}

5. Beta bloqueadores no selectivos (propanolol): Este grupo de fármacos ayudan a disminuir la presión portal, por lo que disminuyen el riesgo de resangrado ${ }^{12}$.

6. Ácido tranexámico: Fármaco derivado del aminoácido lisina, tiene un efecto considerable como antifibrinolítico y previene la degradación de las mallas de fibrina. La evidencia actual muestra que el uso de este fármaco reduce el riesgo de resangrado y la mortalidad en una HDA no variceal, sin incrementar el riesgo tromboembólico. Sin embargo, su uso rutinario en la práctica clínica no ha sido recomendado ya que se necesitan más ensayos clínicos ${ }^{19}$.

Tabla 11. Manejo médico específico por cada etiología de la HDA

\section{Úlcera péptica}

1. Administración de IBP: Bolo de $80 \mathrm{mg}$ IV asociado a infusión continua de $8 \mathrm{mg} / \mathrm{h} \mathrm{IV}$.

2. Erradicación de HP: La erradicación de la bacteria disminuye la probabilidad de resangrado. Tratamiento recomendado:

a. Claritromicina: $500 \mathrm{mg}$ cada $12 \mathrm{~h}$ por 14 días.

b. Amoxicilina: $1 \mathrm{~g}$ cada $12 \mathrm{~h}$ por 14 días.

c. Omeprazol: $20 \mathrm{mg}$ cada $12 \mathrm{~h}$ por 14 días.

En caso de alergia a la penicilina:

a. Metronidazol: $500 \mathrm{mg}$ cada $12 \mathrm{~h}$ por 14 días.

b. Claritromicina: $500 \mathrm{mg}$ cada $12 \mathrm{~h}$ por 14 días.

c. Omeprazol: $20 \mathrm{mg}$ al día por 14 días.

3. Suspender AINES, ISRS y AAS.

\section{Desgarro de Mallory-Weiss}

1. Administración de IBP: bolo de $80 \mathrm{mg}$ IV asociado a infusión continua de $8 \mathrm{mg} / \mathrm{h} \mathrm{IV}$.

2. Antieméticos: Ondansetrón 4-8 mg IV cada 8 h

\section{Várices gastroesofágicas}

1. Administrar vasoconstrictores esplácnicos:

a. Octreotide (análogo de somatostaina) en Bolo de $50 \mathrm{mcg}$ IV asociado a infusión continua de $50 \mathrm{mcg} / \mathrm{h}$ o,

b. terlipresina (análogo de vasopresina):

i. Previo a control de sangrado: $2 \mathrm{mg}$ IV cada 4-6 h

ii. Posterior a control de sangrado: $1 \mathrm{mg}$ IV cada $4-6 \mathrm{~h}$

2. Antibióticos de amplio espectro:

a. Ceftriaxona 2 gramos IV cada 24 h por al menos 7 días

3. Betabloqueadores no selectivos

a. Propranolol $20 \mathrm{mg} / 12 \mathrm{~h}$

\section{Gastritis y Esofagitis erosiva}

1. Administración de IBP: Bolo de $80 \mathrm{mg}$ IV asociado a infusión continua de $8 \mathrm{mg} / \mathrm{h}$ IV. en el momento de la presentación aguda.

2. Se debe indicar uso de IBP oral por 8 a 12 semanas con control endoscópico una vez finalizado el tratamiento médico. ${ }^{31}$

\section{Gastritis por estrés}

1. Administración de IBP: Bolo de $80 \mathrm{mg}$ IV asociado a infusión continua de $8 \mathrm{mg} / \mathrm{h} \mathrm{IV}$.

2. En caso de que lo anterior no de resultado, se puede considerar la posibilidad de administrar vasoconstrictores esplácnicos (octreotide o vasopresina).
En la Tabla 11 se detalla el manejo médico específico por cada etiología de la HDA.

\section{Manejo endoscópico}

El gold standard para el diagnóstico, estratificación del pronóstico y tratamiento de una HDA es la realización de una EDA. Posee una sensibilidad cercana al $98 \%$, y una especificidad que varía entre el $30 \%$ al $100 \%{ }^{20}$. Se ha visto que aquellos pacientes con EDA de menos de 24 horas o en forma precoz, se benefician mucho más que quienes lo hacen en un tiempo mayor. Existe una diferencia significativa entre ambos grupos por una mayor mortalidad, grado de sangrado, mayor tiempo de estadía intrahospitalaria y mayor recidiva de la patología ${ }^{21}$. Con la EDA se logra verificar el sitio del sangrado, el daño de epitelio y mucosas y efectuar la clasificación de Forrest, la cual posiciona a los pacientes, de acuerdo con las variables de resangrado, cirugía y mortalidad, en distintos estratos de riesgo ${ }^{22}$. Para las HDA no variceales se reserva el tratamiento para las lesiones Forrest Ia a IIb (Tabla 12 y Figura 9). Durante la endoscopia, se puede realizar un tratamiento inmediato de forma mecánica, con inyectoterapia, terapia térmica o con spray y clips. En la Tabla 13 se detallan los métodos ${ }^{4}$. En la Tabla 14 se describen los tratamientos específicos de las patologías.

Para las HDA variceales se prefiere el uso de ligaduras dado que producen menos complicaciones. Además, permiten controlar el sangrado en el $90 \%$ de los pacientes con várices esofágicas, Sin embargo, no resultan tan eficaces en el tratamiento de las varices gástricas ${ }^{23}$. Para el caso de las varices gástricas sangrantes, se prefiere el uso de escleroterapia ante ligaduras, ya que ha mostrado mejor eficacia ${ }^{24}$.

Después del tratamiento endoscópico por várices esofágicas se recomienda repetir la EDA hasta que se hayan erradicado las varices, cada 1 o 2 semanas, o hasta que se logre la resolución del cuadro ${ }^{24}$. En caso de fallar la terapia médica y quirúrgica se debe considerar el uso de la derivación portosistémica intrahepática transyugular (TIPS en inglés). Esta es una forma mínimamente invasiva de descomprimir el sistema venoso portal en pacientes con hipertensión portal (Figura 10) ${ }^{18}$.

El tratamiento quirúrgico actualmente es poco frecuente, pero sigue teniendo un $\mathrm{rol}^{3,24}$. Se reserva para los pacientes con hemorragia masiva que no logran estabilización hemodinámica pese a la reanimación ${ }^{3}$, especialmente si la terapia angiográfica no está inmediatamente disponible ${ }^{18}$. Adicionalmente, también está indicado cuando la terapia endoscópica (hasta 2 tentativas de lograr hemostasia endoscópicamente) o el manejo endovascular por radiología 
Tabla 12. Clasificación de Forrest con su necesidad de intervención endoscópica y riesgo de resangrado. Adaptado de Nelms y Pelaez ${ }^{13}$ y Klein y Gralnek ${ }^{31}$

\begin{tabular}{|clcc|}
\hline Clase & Descripción & Intervención endoscópica & Riesgo de resangrado \\
IA & Hemorragia arterial activa en Jet o pulsátil & $\mathrm{Si}$ & $55-90 \%$ \\
IB & Hemorragia arterial activa en napa o goteo & $\mathrm{Si}$ & $55-90 \%$ \\
\hline IIA & Vaso visible al fondo de la úlcera no sangrante & $\mathrm{Si}$ & $43-50 \%$ \\
IIB & Coágulo adherido a la base de la úlcera & Se puede considerar & $22-33 \%$ \\
IIC & Mancha plana cubierta de hematina & No & $10 \%$ \\
III & Úlcera con base limpia & No & $5 \%$ \\
\hline
\end{tabular}
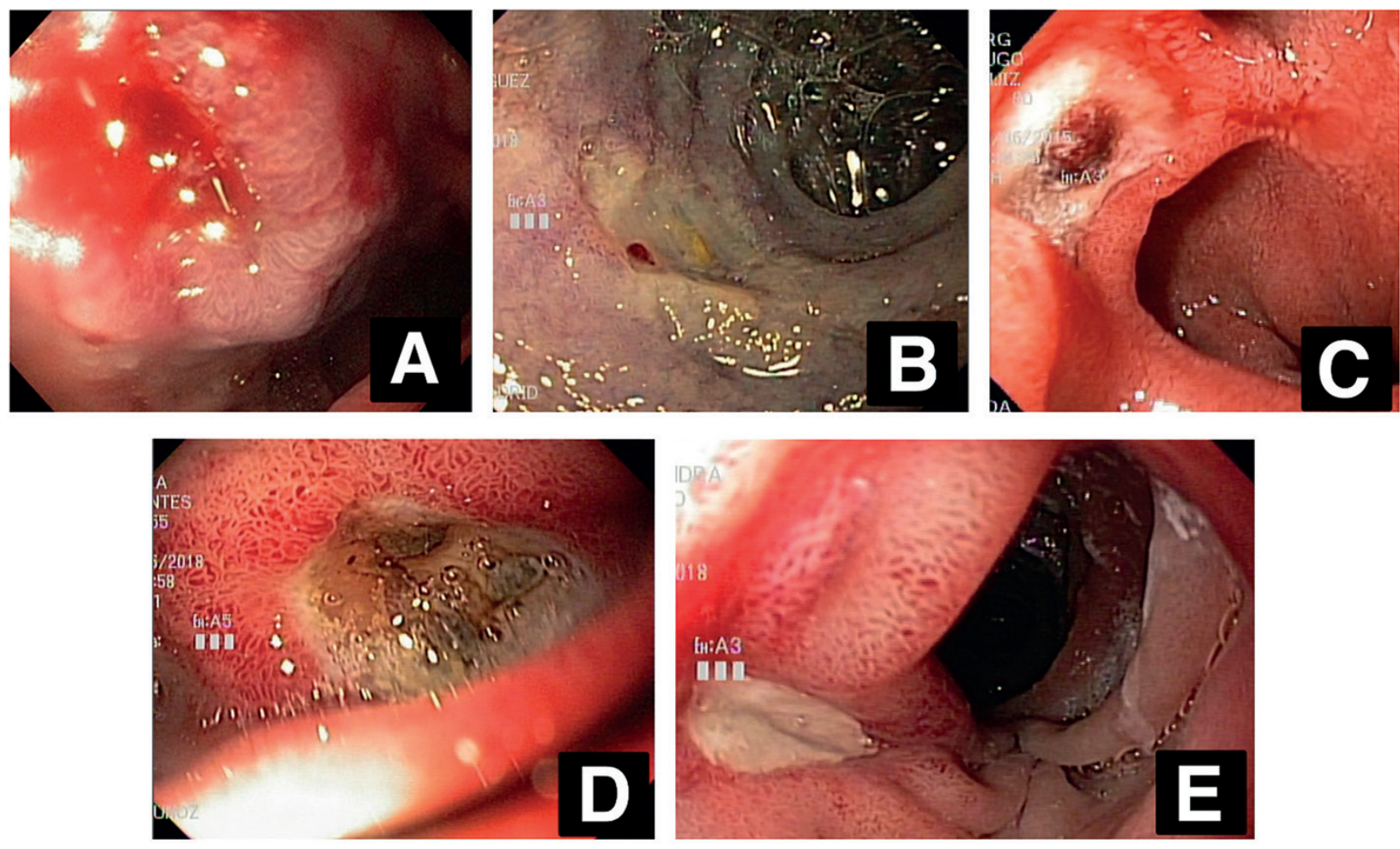

Figura 9. Clasificación de Forrest para las úlceras pépticas visualizadas de manera endoscópica. En la imagen A sangrado en napa o goteo (Forrest IB). En la imagen B se observa vaso visible no sangrante (Forrest IIA). En la imagen C se observa coágulo adherido a la base de la úlcera (Forrest IIB). En la imagen D se observa una mancha plana pigmentada (Forrest IIC). En la imagen E se observa una úlcera de base limpia (Forrest III). Gentileza del equipo de gastroenterología y endoscopia HCUCh.

Tabla 13. Medidas terapéuticas usadas en la EDA. Adaptada de Weitz y cols. ${ }^{3}$

Opciones terapéuticas para hemostasia endoscópica más utilizados

Tratamiento con inyectoterapia: Solución salina, epinefrina, esclerosantes (alcohol, monoetanolamina, polidocanol), trombina (con o sin fibrina), cianoacrilatos.

Tratamiento con electrocoagulación (térmico), existen dos tipos:

1. De contacto: Sondas calientes, de electrocoagulación mono o bipolares.

2. Sin contacto: Coagulación con Argón plasma, Láser Nd-YAG.

Tratamiento mecánico: Hemoclips, over-the-scope clip (OTSC), ligaduras.

Tratamiento tópico: Polvos hemostáticos endoscópicos en forma de spray. 
Tabla 14. Manejo intervencional específico para cada etiología de la HDA

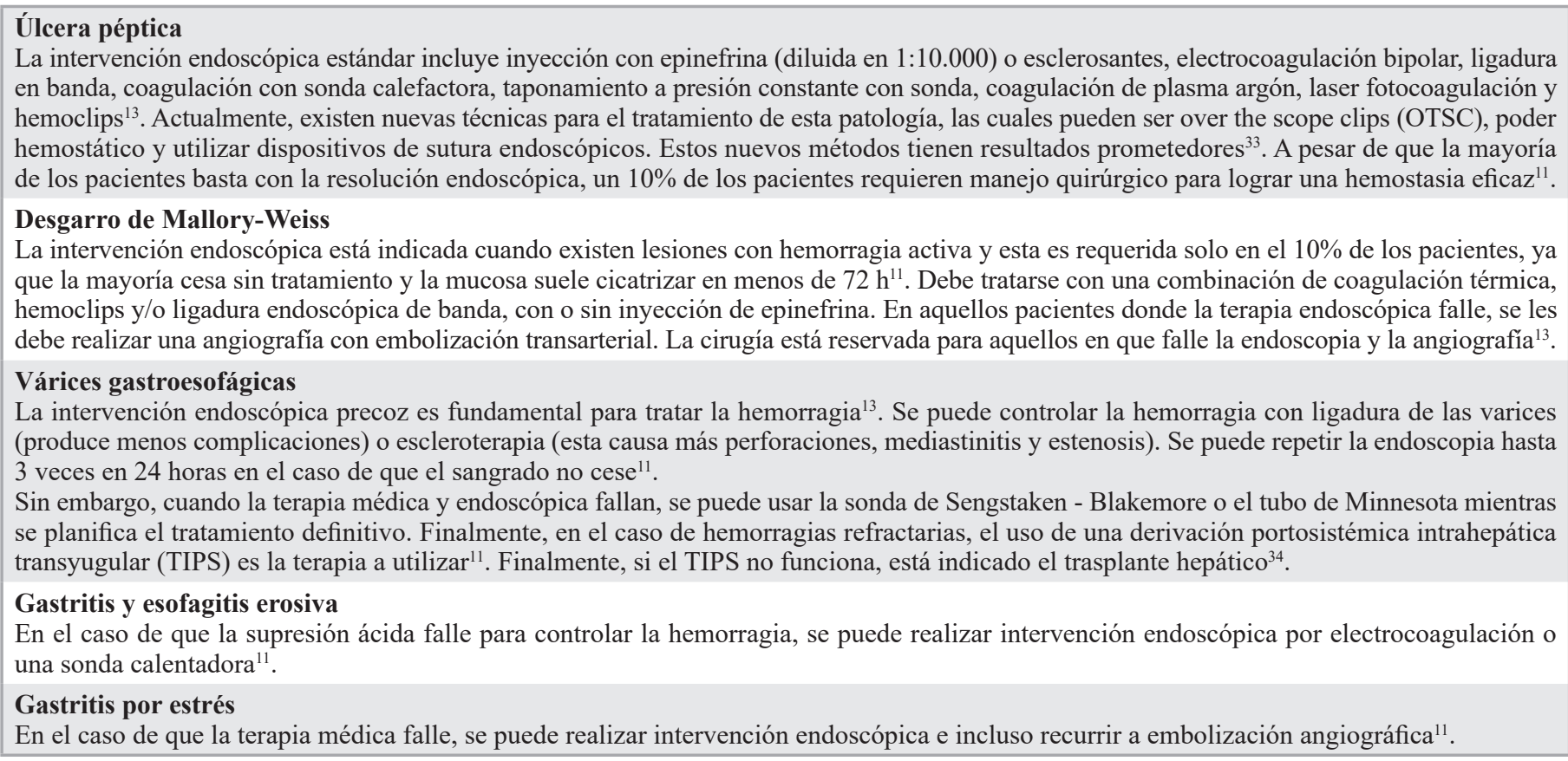

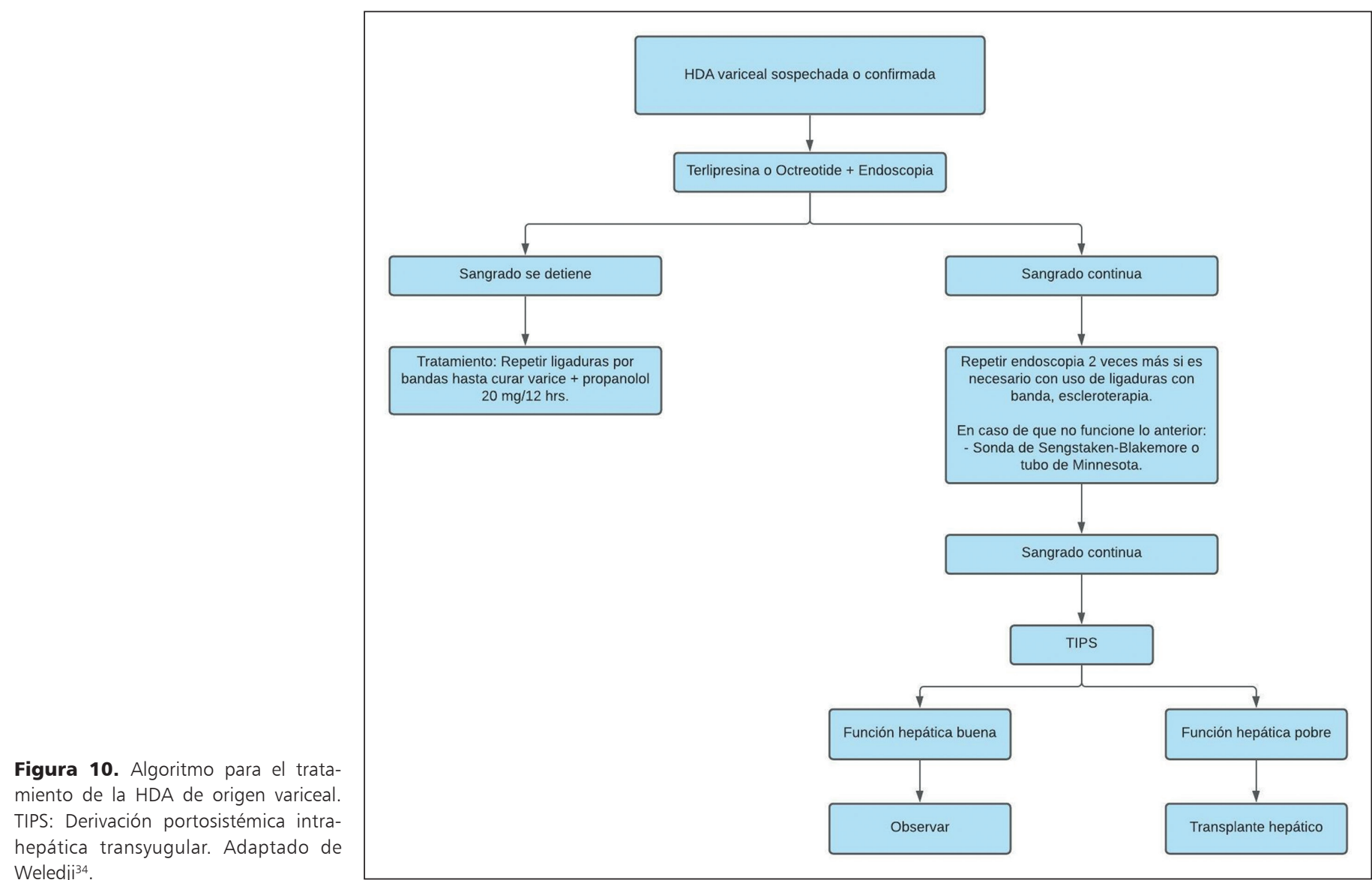


intervencional fallan ${ }^{3,13,25}$. En la Tabla 15 se muestran las indicaciones clásicas para el tratamiento quirúrgico de la hemorragia digestiva.

Actualmente, los pacientes que llegan al servicio de urgencias con una HDA que presentan neumonía por COVID-19 es algo desafiante. Porque hay una gran preocupación por la transmisión del virus en el procedimiento por parte de los anestesiólogos, endoscopistas y el resto del equipo, debido a la aerosolización del virus durante el procedimiento de la EDA. Se ha reportado en la literatura que existe la posibilidad de tratar a los pacientes de manera conservadora (IBP endovenoso, transfusiones sanguíneas a necesidad y una frecuente monitorización de los signos vitales) sin una EDA si, y sólo si, los pacientes responden dentro de las 24 horas. Lamentablemente, pocos pacientes responden a este tratamiento conservador dentro del tiempo establecido. Por lo cual, se indica la EDA, en donde el equipo debe realizarla con equipo de protección personal ${ }^{26}$.

\section{Manejo posendoscópico}

Los objetivos de realizar un tratamiento médico postendoscópico son reducir el riesgo de resangrado mientras se cura la úlcera o lesión y prevenir las recidivas a largo plazo ${ }^{4}$. Un modo consiste en la administración precoz de inhibidores de la bomba de protones o IBP (omeprazol, lansoprazol) endovenoso, con tal de mantener un $\mathrm{pH}$ cercano a 6 o cifras mayores, pues se ha visto una mejor sobrevida en aquellos pacientes que reciben esta forma de administración versus oralmente ${ }^{25}$. Otro aspecto del tratamiento médico es la erradicación de HP, siendo la erradicación de este factor de riesgo el de mejor efectividad a largo plazo en prevenir recidivas de sangrado (terapia triestándar con omeprazol $20 \mathrm{mg} / 12$ h, amoxicilina/ácido clavulánico $1 \mathrm{~g} / 12 \mathrm{~h}$, claritromicina $500 \mathrm{mg} / 12 \mathrm{~h}$ por 14 días) ${ }^{27}$. Por último, se menciona que el uso de AINEs no selectivos aumenta el riesgo de sangrado, lo cual disminuye con el uso en conjunto de IBP. Además, se ha visto que el reemplazo por inhibidores selectivos de COX-2 ha disminuido también la recurrencia de sangrado. Se recomienda como primera línea entonces el uso de inhibidores selectivos de COX-2 junto con algún IBP de última generación para disminuir la recidiva de sangrado en pacientes después de realizada la endoscopia ${ }^{28,29}$.

\section{Conclusiones}

La HDA es una patología de alta morbilidad y mortalidad. La disminución de su incidencia a nivel mundial se puede explicar por los nuevos trata-
Tabla 15. Indicaciones para cirugía en HDA. Adaptado de Tavakkoli y Ashley ${ }^{11}$

Indicaciones para la cirugía en pacientes con HDA

Inestabilidad hemodinámica a pesar de reanimación vigorosa (transfusiones $>6$ unidades).

Imposibilidad de detener la hemorragia con técnicas endoscópicas.

Recidiva de la hemorragia tras la estabilización inicial (hasta dos tentativas de lograr la hemostasia endoscópicamente).

Shock asociado a hemorragia recurrente.

Hemorragia lenta y continuada con necesidad de transfusión de más de 3 unidades/día.

mientos tanto médicos como quirúrgicos, o por un mejor manejo con escalas validadas y en constante actualización. Por un lado, el manejo médico consta de IBP, vasoconstrictores, AINEs selectivos y otros fármacos que ayudan a contener la hemorragia. Por el otro, el manejo quirúrgico comprende múltiples procedimientos, siendo el gold standard la endoscopía digestiva alta para el manejo y tratamiento de una HDA. Se concluye finalmente la importancia de conocer el manejo de esta patología cuando un paciente acude con este síndrome, donde inmediatamente se le debe brindar una evaluación primaria (manejo de urgencia) y una evaluación secundaria, en donde se terminará la historia clínica y se decidirá la conducta a seguir, conduciendo finalmente al pronóstico y tratamiento de la patología.

\section{Responsabilidades éticas}

Protección de personas y animales. Los autores declaran que para esta investigación no se han realizado experimentos en seres humanos ni en animales.

Confidencialidad de los datos. Los autores declaran que en este artículo no aparecen datos de pacientes.

Agradecimientos: Agradecimiento al Departamento de Gastroenterología y Endoscopía del Hospital Clínico Universidad de Chile, en especial al Dr. Cristián Montenegro por el aporte de imágenes originales a esta revisión. Agradecimiento especial a la Dra. Emilia Sanhueza Reinoso, profesora asociada del Programa de Fisiopatología del ICBM, Facultad de Medicina, Universidad de Chile, Santiago, Chile, por la colaboración en la elaboración de los esquemas de la fisiopatología de la infección de $H$. pylori y AINEs, y revisión del manuscrito.

Conflictos de interés: no hay. 


\section{Bibliografía}

1. Jafar W, Jafar A, Sharma A. Upper gastrointestinal haemorrhage: an update. Frontline Gastroenterology 2014;7:32-40.

2. Srygley F, Gerardo C, Tran T, Fisher D. Does This Patient Have a Severe Upper Gastrointestinal Bleed? JAMA 2012;307:1072-9.

3. Weitz J, Berger Z, Sabah S, Silva H, Riquelme A. Diagnóstico y tratamiento de enfermedades digestivas. 2017 (3.a ed.).ISBN: 978-956-7936-34-2.

4. Lanas A, Dumonceau J, Hunt R, Fujishiro M, Scheiman J, Gralnek I, et al. Nonvariceal upper gastrointestinal bleeding. Nature Reviews Disease Primers 2018;4:18020. doi: 10.1038/nrdp.2018.20.

5. Patel V, Nicastro J. Upper Gastrointestinal Bleeding. Clinics in Colon and Rectal Surg 2019;33:42-4.

6. Gralnek I, Dumonceau J, Kuipers E, Lanas A, Sanders D, Kurien M, et al. Diagnosis and management of nonvariceal upper gastrointestinal hemorrhage: European Society of Gastrointestinal Endoscopy (ESGE) Guideline. Endoscopy 2015;47:a1-a46.

7. Rotondano G. Epidemiology and Diagnosis of Acute Nonvariceal Upper Gastrointestinal Bleeding. Gastroenterology Clinics of North America 2014;43:643-63.

8. Abougergi M, Travis A, Saltzman J. The in-hospital mortality rate for upper GI hemorrhage has decreased over 2 decades in the United States: a nationwide analysis. Gastrointestinal Endoscopy 2015;81:882-88. e1.

9. Pavez C, Padilla O, Araya R. Evaluación de la Clasificación de Rockall como predictor de mortalidad en pacientes con hemorragia digestiva alta de origen no variceal. Gastroenterol Latinoam, 2010;21:476-84.

10. Pinto C, Parra P, Magna J, Gajardo A, Berger Z, Montenegro C, et al. Hemorragia digestiva alta variceal y no variceal: mortalidad intrahospitalaria y características clínicas en un hospital universitario (2015-2017). Rev Med Chile 2020;148:288-94.

11. Martínez G, Csendes A, Carreño B. Hemorragia Digestiva Alta. En Rojas Duarte M, Marinkovic B. Cirugía en medicina general, manual de enfermedades quirúrgicas. Santiago: Universidad de Chile; 2020. p. 99-115.

12. Nelms D, Pelaez C. The Acute Upper Gastrointestinal Bleed. Surgical Clinics of North America. 2018;98:1047-57.

13. Baradarian R, Ramdhaney $\mathrm{S}$, Chapalamadugu R, Skoczylas L, Wang K, Rivilis S, et al. Early Intensive Resuscitation of Patients With Upper Gastrointestinal Bleeding Decreases Mortality. Am J Gastroenterology 2004;99:619-22.

14. Loperfido S, Baldo V, Piovesana E, Bellina L, Rossi K, Groppo M, et al. Changing trends in acute upper-GI bleeding: a population-based study. Gastrointest Endosc. 2009;70:212-24.

15. Wee E. Management of nonvariceal upper gastrointestinal bleeding. J Postgraduate Med 2011;57:161-7.

16. Rickard A, Squire R, Freshwater DA. Validation of the Glasgow Blatchford Score to enable safe discharge of selected patiens with upper GI bleeding. J R Nav Med Serv. 2012;98:12-4.

17. Recio-Ramírez JM, Sánchez-Sánchez MP, Peña-Ojeda JA, Fernández-Romero E, Aguilera-Peña M, del-Campo-Molina E, et al. Capacidad predictiva de la escala de Glasgow-Blatchford para la estratificación del riesgo de la hemorragia digestiva alta en un servicio de urgencias. Rev Esp Enferm Dig. 2015;107:262-67.

18. Feinman M, Haut E. Upper Gastrointestinal Bleeding. Surgical Clinics of North America. 2014;94:43-53.

19. Alzoubaidi D, Lovat L, Haidry R. Management of non-variceal upper gastrointestinal bleeding: where are we in 2018?. Frontline Gastroenterology 2018;10:35-42.

20. Kim D, Chung W, Lee S, Sung H, Woo S, $\mathrm{Kim} \mathrm{H}$, et al. Analysis of risk factor and clinical characteristics of angiodysplasia presenting as upper gastrointestinal bleeding. The Korean Journal of Internal Medicine 2016;31:669-77.

21. Klein A, Gralnek I. Acute, nonvariceal upper gastrointestinal bleeding. Current Opinion in Critical Care 2015;21:154-62.

22. Forrest J, Finlayson N, Shearman D. Endoscopy in gastrointestinal bleeding. The Lancet. 1974;304(7877):394-97

23. Tavakkoli A, Ashley SW. Hemorragia digestiva aguda. En CM Townsend, BM Evers, RD Beauchamp \& KL Mattox,
Sabiston. Tratado de cirugía. Fundamentos biológicos de la práctica quirúrgica moderna. $20^{\circ}$ Ed. Barcelona, España: Elsevier. 2018. p. 1139-59.

24. Hwang J, Fisher D, Ben-Menachem T, Chandrasekhara V, Chathadi K, Decker $\mathrm{G}$, et al. The role of endoscopy in the management of acute non-variceal upper GI bleeding. Gastrointestinal Endoscopy 2012;75:1132-38.

25. Laine L, McQuaid K. Endoscopic Therapy for Bleeding Ulcers: An Evidence-Based Approach Based on Meta-Analyses of Randomized Controlled Trials. Clinical Gastroenterology and Hepatology. 2009;7:33-47.

26. Cavaliere K, Levine C, Wander P, Sejpal D, Trindade A. Management of upper GI bleeding in patients with COVID-19 pneumonia. Gastrointestinal Endoscopy 2020;92:454-55.

27. Gisbert J, Khorrami S, Carballo F, Calvet X, Gené E, Dominguez-Muñoz J. H. pylori eradication therapy vs. antisecretory non-eradication therapy (with or without long-term maintenance antisecretory therapy) for the prevention of recurrent bleeding from peptic ulcer. Cochrane Database Syst Rev. 2004;:CD004062.

28. Chan F, Wong V, Suen B, Wu J, Ching J, Hung L, et al. Combination of a cyclooxygenase-2 inhibitor and a proton-pump inhibitor for prevention of recurrent ulcer bleeding in patients at very high risk: a double-blind, randomised trial. The Lancet. 2007;369(9573):1621-26.

29. Laine L. Upper Gastrointestinal Bleeding Due to a Peptic Ulcer. New England Journal of Medicine. 2016;374:2367-76.

30. Baxter M, Aly E. Dieulafoy's lesion: current trends in diagnosis and management. The Annals of The Royal College of Surgeons of England 2010;92:548-54.

31. Allen A, Flemström G. Barrera de bicarbonato del moco gastroduodenal: protección contra el ácido y la pepsina. J Phys Cell Physiol. 2005;288:C1-19.

32. Yang Y, Wu W, Tai E, Wong H, Lam E, So W, et al. The Cationic Host Defense Peptide rCRAMP Promotes Gastric Ulcer Healing in Rats. Journal of Pharmacology and Experimental Therapeutics. 2006;318:547-54.

33. Pai R, Soreghan B, Szabo I, Pavelka M, 
Baatar D, Tarnawski A. Prostaglandin E2 transactivates EGF receptor:

A novel mechanism for promoting colon cancer growth and gastrointestinal hypertrophy. Nature Medicine 2002;8:289-93.

34. Fornai M, Antonioli L, Colucci R, Tuccori M, Blandizzi C. Pathophysiology of Gastric Ulcer Development and Healing: Molecular Mechanisms and Novel Therapeutic Options. Peptic Ulcer Disease. 2011;10:5772-749.

35. Liu Y. Gastrin $(G)$ cells and somatostatin (D) cells in patients with dyspeptic symptoms: Helicobacter pylori associated and non-associated gastritis. J Clin Pathol 2005;58:927-31.

36. Biecker E, Heller J, Schmitz V, Lammert F, Sauerbruch T. Diagnosis and management of upper gastrointestinal bleeding. Dtsch Arztebl Int. 2008;105:8594.

37. Spahn D, Bouillon B, Cerny V, Duranteau J, Filipescu D, Hunt B, et al. The European guideline on management of major bleeding and coagulopathy following trauma: fifth edition. Critical Care 2019;23:98. doi.org/10.1186/s13054-
019-2347-3.

38. Ebrahimi-Bakhtavar H, Morteza-Bagi HR, Rahmani F, Shahsavari Nia K, Ettehadi A. Clinical Scoring Systems in Predicting the Outcome of Acute Upper Gastrointestinal Bleeding; a Narrative Review. Emerg (Tehran) 2017;5:e36.

39. Lau L, Sung J. Treatment of upper gastrointestinal bleeding in 2020: New techniques and outcomes. Digestive Endoscopy 2020;33:83-94.

40. Weledji E. Acute upper gastrointestinal bleeding: A review. Surgery in Practice and Science. 2020;1:100004. 